\title{
MRS
}

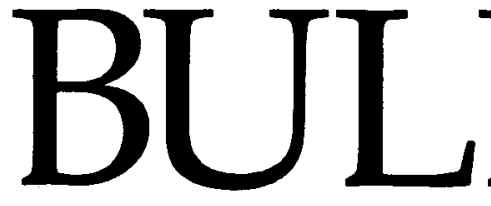

$\mathrm{L}$
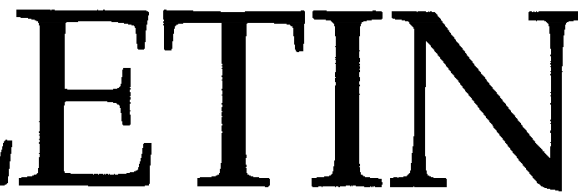

Materials Research Society

Vol. IX No. 1

January/February 1984

\section{FIRST MRS SPRING MEETING}

Four Symposia Are Slated To Be Offered In Albuquerque,
Site Of The Society's First-Ever Supplement To Boston

The Materials Research Society's first of a planned annual series of Spring Meetings is being held in Albuquerque, New Mexico, Feb. 27-29. The Society is extremely pleased to report that, through the efforts of Program Chairmen Gordon Pike of Sandia National Labs, Ross Lemons of Los Alamos National Lab, and Noble Johnson of Xerox's Palo Alto, Calif., Research Center, a large number of materials scientists based in Western North America, Latin America, and the Far East have a supplement to the Society's November Annual Meeting in Boston, Massachusetts, for topical symposia of particular interest at government, industry and university labs in those areas.

\section{Some 300 Expected to Attend}

The level of preregistrations indicates total enrollment at the Albuquerque Meeting will be about 300 scientists, engineers, and technicians. Last-minute registrations could well push the figure higher. This indicates the meeting, being held at the Albuquerque Marriott Hotel, is being well received by the materials community.

"The great interest expressed in this meeting has demonstrated the MRS was correct to establish the Spring Meetings," the Chairmen report. With more than 1,600 scientists and engineers attending the most recent Annual Meeting in Boston, that conference had grown unwieldy, it was felt. In some instances limitations of space had made it impossible to offer all of the symposia that might have been organized.

Also, "The MRS can better serve research topics where the predominant interest is at western universities and industries" through the West Coast meeting, the Chairmen state. "For topics of widest interest, the Spring Meeting will provide the option of site alternation with Boston and symposia repeat time of 18 months."

\section{Four Symposia Scheduled}

Four symposia are being offered at Albuquerque.
Symposium A is "Materials for Display and Printing Technologies," chaired by Derek B. Dove of International Business Machines Corp.'s Yorktown Heights, New York, Research Center, and Cecil E. Land of Sandia National Laboratories. Sessions have been organized on liquid crystal displays, flat panel phosphor displays and phosphor materials, PLZT materials and devices, electrophoretic and electrochromic displays, electroluminescent displays, electrophotographic printing technologies, magnetic, ion-jet

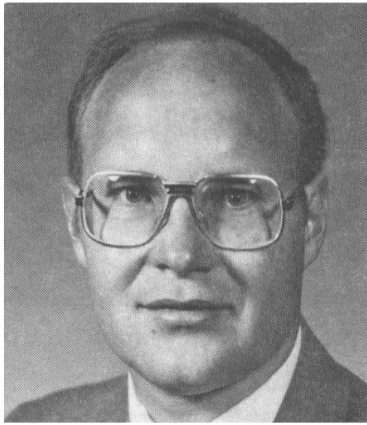

ROSS LEMONS and thermal printing technologies, and ink-jet printing technology.

Symposium B is "Better Ceramics Through Chemistry." The Chairmen are C. Jeff Brinker of Sandia National Labs, David E. Clark of the University of Florida, Gainesville, and D.R. Ulrich of the Air Force Office of Scientific Research. Sessions include the science of sol-gel processing, applications of sol-gel processing, chemical synthesis of ceramic powders, novel materials through chemical synthesis, and characterization of gels and powders.

Symposium C is "Optical and Magnetic Data Storage Materials," chaired by Geoffrey Bate of Verbatim Corp., Martin A. Bosch of Bell Laboratories, and Nobutake Imamura of KDD R\&D Laboratories. The spread of computers places severe demands on the capacity and cost of data storage equipment, and this symposium will include two sessions each on magnetic-the technology with the longer history-and optical data storage technologies.

Symposium D, "Comparison of Thin Film Transistor and 
evidence. A National Science Foundation-funded study by Princeton University two years ago found that 83 percent of workers in the radwaste area agree that present technology is effective in the safe control of these wastes. The research of Rothman and Lichter (see "The Nuclear Energy Debate: Scientists, the Media and the Public," Public Opinion, August-September 1982) shows that scientists support nuclear power, and that the opinions of such groups as the Union of Concerned Scientists are reported out of proportion to their numbers.

\section{A Back-Door Endorsement of Coal}

The role of the media in reporting the nuclear-power controversy amounts to a back-door endorsement of coal. Given the stated concerns about health and the environment, this is a paradox. Can the nuclear industry be accused of contributing to as many deaths? A death due to radioactivity in a nuclear power plant would be a major story, would there be one. There hasn't. A death in a coal mine, however lamentable, is not very remarkable. There are too many.

The Office of Technology Assessment reported (July 1982) that as many as 51,000 premature deaths annually may be due to $\mathrm{SO}_{2}$ inhalation from emissions from coal-fired power plants. Add to these the number of premature deaths due to other oxides (mainly carbon and nitrogen), the long- range effects of large quantities of carcinogenic trace elements concentrated in coal that are released during burning, the suffering of miners from black lung and other respiratory ailments, the plight of roughly one quarter of the contiguous United States from acid rain, the ever-drawingnearer greenhouse effect, and the plethora of adverse health effects associated with the transportation and processing of coal, and one is baffled as to how the role of villain was assigned, and for what reasons.

Very obviously, the media and the public fear some kind of nuclear catastrophe, and seem willing to exchange these tens of thousands of lives for protection from it. Such a catastrophe, based on 20 years of operation, appears to be more and more unlikely. Based on present evidence, these victims are being sacrificed for nothing.

Sadly, little is being done to educate the public about the scientific basis of nuclear power development and radioactive waste disposal. In my opinion, government and industry should have initiated such educational programs in the 1950s. But it is not too late to catch up. Other nations, notably Canada, have embraced nuclear power enthusiastically, safely, economically, and with broad public support. Nuclear power is the safest form of generally available energy. The task is to build a consensus for its development.

\section{ALBUQUERQUE}

\section{[Continued from Page 1]}

SOI Technologies," is chaired by Hon Wai Lam of Texas Instruments and Malcom J. Thompson of Xerox Corp.'s Palo Alto Research Center. Sessions are offered on SOI for LSI and VLSI, beam-recrystallized SOI, beam recrystallization devices and $3 \mathrm{D}$ integration, polysilicon and polysilicon thin film transistors, thin film technology and large-area applications, and TFT materials.

\section{The Program Chairmen}

The Program Chairmen have long been active in MRS conferences.

Gordon Pike has been especially busy, having served as Co-Chairman of the 1983 Annual Meeting in Boston. With degrees from CarnegieMellon and the University of Pittsburgh, he has spent his career at Sandia, doing research that has ranged from superconductivity and radiation effects in MOSFET transistors to conductive elastomers and electronic properties of semiconductor grain

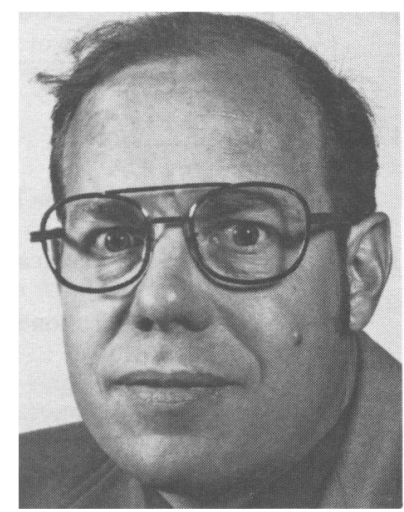

GORDON PIKE boundaries.

Ross Lemons, the inventor of the scanning acoustic microscope, took his Ph.D. from Stanford. Before joining
Los Alamos in 1982, he was a member of the technical staff at Bell Laboratories. His research interests include electrochromic materials, ferroelectric-ferroelastic devices, magnetostatic wave propagation, thin film silicon crystallization, and electrically amplified optical recording.

Noble Johnson, a Co-Chairman of the symposium on energy beam-solid interactions and transient thermal processing at the 1983 MRS Annual Meeting, has a Ph.D. from Princeton. Before joining Xerox, he was associated with the radiation physics group of the Poulter Laboratory of SRI International and with the RCA Research Laboratories in Princeton.

\section{Future Spring Meetings}

West-coast MRS meetings will be held annually in the

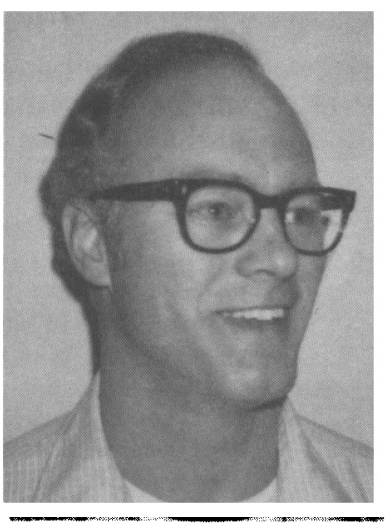

NOBLE JOHNSON spring. As reported elsewhere in these pages, the next one will be in San Francisco. It is set for March 1985. "Together with the expansion of the Annual Meeting in Boston," notes MRS President C.W. "Woody" White of Oak Ridge National Lab, "the Spring Meetings greatly enhance the technical conferences the Society provides to the materials science community. They reinforce our premier position as the professional organization for materials scientists and engineers." 